Pancasakti Science Education Journal

\title{
Profil Kemampuan Berpikir Kritis Siswa dengan Implementasi Model Pembelajaran SETS Berbasis Probing-Prompting
}

\author{
Mega Sylviana $^{1}$, Mobinta Kusuma ${ }^{2}$, Bayu Widiyanto ${ }^{3}$ \\ ${ }^{1,2,3}$ Prodi Pendidikan IPA, Fakultas Keguruan dan Ilmu Pendidikan, Universitas Pancasakti Tegal, \\ Indonesia
}

Korespondensi. E-mail: mega sylviana@upstegal.ac.id

\begin{abstract}
Abstrak
Penelitian bertujuan untuk mengetahui profil kemampuan berpikir kritis siswa dengan implementasi model pembelajaran SETS berbasis probing-prompting. Populasi dalam penelitian ini adalah siswa kelas VII SMP N 8 Pekalongan. Desain dalam penelitian adalah pretest-posttest. Metode pengambilan data yang digunakan adalah tes tertulis berupa pilihan ganda. Pengujian profil kemampuan berpikir kritis dilakukan melalui analisis kemampuan dengan menghitung selisih antara kemampuan awal dan akhir. Hasil penelitian profil kemampuan berpikir kritis siswa dengan implementasi model SETS berbasis probing-prompting meningkat yaitu pretest $72.5 \%$ dan posttest $82.9 \%$ atau dengan selisih sebesar $10.4 \%$.
\end{abstract}

Kata Kunci: Kemampuan berpikir kritis; SETS; Probing-prompting

\section{Attitudes and Motivation of Students in Physics in Senior High School}

\begin{abstract}
The study aims to determine the profile of students' critical thinking skills with the implementation of the SETS based probing-prompting learning model. The population in this study was VII grade students of SMP N 8 Pekalongan. The design in this research is pretest-posttest. The data collection method used is a written test in the form of multiple choice. Testing the profile of critical thinking skills is done through the analysis of abilities by calculating the difference between initial and final abilities. The results of the study of the critical thinking ability of students with the implementation of SETS based probing-prompting models increased namely pretest $72.5 \%$ and posttest $82.9 \%$ or by a difference of $10.4 \%$.
\end{abstract}

Keywords: Critical thinking skill; SETS; Probing-prompting 


\section{PENDAHULUAN}

Belajar adalah kegiatan berlatih. Sedangkan pembelajaran adalah kegiatan tanya jawab antara guru dan siswa. Pembelajaran melatih kemampuan berpikir siswa serta pemberian teladan dalam pengetahuan. Hal tersebut dilakukan agar siswa dapat menemukan jawaban atas permasalahan yang sedang atau akan dihadapi sehingga dapat menguasai pengetahuan dasar yang diterima, serta dapat mengembangkan karakter dan bakat-bakatnya (Tim Pengembang MKDP, 2011). Kemampuan berpikir penting dimiliki oleh siswa. Hal tersebut dikarenakan dalam proses pembelajaran siswa akan selalu dituntut untuk berpikir.

Berpikir dilakukan oleh seseorang untuk mempertimbangkan atau memutuskan sesuatu. Sedangkan berpikir kritis merupakan kegiatan menganalisis suatu ide atau gagasan, membedakannya, memilih, mengidentifikasi, mengkaji dan mengembangkannya ide atau gagasan ke arah yang lebih spesifik dan sempurna (Wahyuni, 2015). Kemampuan berpikir kritis diperlukan agar siswa dapat menganalisis permasalahan. Sehingga siswa mampu mencapai tahap pencarian solusi untuk menyelesaikan permasalahan. Untuk itu idealnya kemampuan seseorang yang berpikir kritis memiliki kemampuan untuk fokus pada pertanyaan, menganalisis argumen, bertanya dan menjawab klarifikasi atau tantangan dari pertanyaan, mempertimbangkan kredibilitas dari sebuah sumber, mengamati dan mempertimbangkan pengamatan laporan, menyimpulkan dan mempertimbangkan deduksi, membuat kesimpulan materi, membuat dan mempertimbangkan nilai, menentukan syarat dan mempertimbangkan definisi, mengidentifikasi asumsi,serta membuat dan membela keputusan (Ennis, 2011). Proses berpikir kritis sangat berkaitan dengan kemampuan pemahaman konsep pada siswa (Kusuma, 2016). Berpikir kritis dapat dilakukan dengan cara menerapkan model pembelajaran yang mampu melatih siswa untuk terlibat dan aktif dalam proses pembelajaran, mampu mengatasi permasalahan, dan berpusat pada siswa (students centered learning).

Salah satu model pembelajaran yang berpusat pada siswa dan mampu mengatahsi permasalahan adalah SETS. SETS memiliki 4 komponen yang dikaitkan dengan pembelajaran yaitu science (sains), technology (teknologi), environment (lingkungan) dan society (masyarakat). SETS diharapkan dapat meningkatkan kemampuan berpikir kritis dan pengambilan keputusan dalam suatu isu atau permasalahan (Steele, 2013). Model pembelajaran SETS merupakan model yang mengembangkan kemampuan kognitif, afektif dan psikomotor yang dibentuk dalam diri sebagai siswa, dengan harapan dapat diaplikasikan dalam kehidupan sehari-hari (Aprianingtyas \& Sumadi, 2017).

Selain model pembelajaran SETS terdapat teknik pembelajaran yang dapat digunakan sebagai sarana pendukung siswa terlibat dalam proses pembelajaran, diantaranya adalah teknik probing-prompting. Probing-prompting adalah teknik pembelajaran yang dilakukan dengan menyajikan beberapa pertanyaan yang sifatnya menuntun dan menggali gagasan siswa. Digunakan agar siswa mampu menghubungkan pengalaman dengan pengetahuan baru yang akan mereka pelajari (Huda, 2014). Perpaduan antara model pembelajaran SETS berbasis probing-prompting tersebut, diharapkan dapat meningkatkan kemampuan berpikir kritis siswa.

Berdasarkan uraian yang telah dijabarkan, maka tujuan yang ingin dicapai pada penelitian ini adalah untuk mengetahui bagaimana profil kemampuan berpikir kritis siswa setelah implementasi model pembelajaran.

\section{METODE}

Penelitian ini dilaksanakan di SMP N 8 Pekalongan. Metode penelitian yang digunakan adalah pretest-posttest. Pretest-posttest merupakan desain yang membandingkan tes awal dengan tes akhir (Susongko, 2015). Populasi dalam penelitian ini adalah siswa kelas VII tahun ajaran 2018/2019, dengan jumlah 229 siswa 


\section{Pancasakti Science Education Journal, 4 (2), Oktober 2019- (139)}

Mega Sylviana, Mobinta Kusuma, Bayu Widiyanto

yang terbagi dalam 7 kelas. Sampel dalam penelitian ini diperoleh dengan teknik purposive sampling.

Metode pengumpulan data dalam penelitian ini menggunakan tes pilihan ganda. Tes pilihan ganda yang digunakan merupakan tes yang telah diuji dan dinyatakan valid serta reliabel melalui uji rasch model. Tes pilihan ganda digunakan sebagai tes kemampuan awal (pretest) dan kemampuan akhir (posttest).

\section{HASIL DAN PEMBAHASAN}

Pengujian dilakukan untuk mengetahui profil kemampuan berpikir kritis siswa dengan implementasi model pembelajaran SETS berbasis probing-prompting. Kemampuan berpikir kritis diperlukan agar seorang siswa dapat menganalisis suatu permasalahan yang ada atau yang diberikan hingga pada tahap pencarian solusi untuk menyelesaikan suatu permasalahan. Kemampuan berpikir kritis yang akan diukur dalam penelitian ini meliputi : (1) menganalisis pertanyaan; (2) menjawab klarifikasi atau tantangan pertanyaan; (3) mengamati dan mempertimbangkan pengamatan; dan (4) menyimpulkan dan mempertimbangkan kesimpulan.

Pengujian dalam penelitian ini dilakukan menggunakan bantuan software $\mathrm{R}$ program dan Ms. excel. $\mathrm{R}$ program digunakan untuk pengujian instrumen, yaitu untuk mengetahui soal yang valid, tingkat kesukaran serta tingkat reliabel. Berdasarkan uji soal yang dilakukan diperoleh hasil tingkat kesukaran soal yang dapat dilihat pada tabel 1 .

\section{Tabel 1. Tingkat Kesukaran Soal}

\begin{tabular}{|c|c|c|c|c|}
\hline \multirow{2}{*}{$\begin{array}{c}\text { Tingkat } \\
\text { Kesukaran } \\
(I R T)\end{array}$} & \multicolumn{2}{|c|}{ Pertemuan Pertama } & \multicolumn{2}{|c|}{ Pertemuan Kedua } \\
\hline & Pretest & Posttest & Pretest & Posttest \\
\hline Sukar & - & 3,6 & 10 & 5 \\
\hline Sedang & $\begin{array}{l}2,3,6,7, \\
10\end{array}$ & $2,4,5,7,8,9,10$ & $\begin{array}{l}2,3,4,6,7 \\
8,9\end{array}$ & $1,3,6,9,10$ \\
\hline Mudah & $1,4,5$ & 1 & 1,5 & $2,4,7,8$ \\
\hline
\end{tabular}

Berdasarkan Tabel 1, soal yang digunakan telah diuji validitasnya menggunakan rasch model. Sedangkan soal yang digunakan menurut Hambleton \& Swaminathan (1985) adalah soal yang masuk dalam kriteria mudah hingga sukar. Apabila soal terlalu sukar maka fungsi ukur tidak dapat dilakukan dengan baik. Hal tersebut diperkirakan siswa akan cenderung menjawab dengan tebakan. Sedangkan soal yang terlalu mudah merupakan soal yang perlu direvisi atau tidak dapat digunakan.

Selain validitas dan tingkat kesukaran, reliabilitas juga merupakan syarat penting dalam pengambilan soal yang akan digunakan. Hasil reliabilitas soal dapat dilihat pada Tabel 2.

Tabel 2 Hasil Reliabilitas

\begin{tabular}{ccccc}
\hline & \multicolumn{3}{c}{ TES } \\
\cline { 2 - 5 } & \multicolumn{3}{c}{$\boldsymbol{P} \mathbf{1}$} & \multicolumn{2}{c}{$\boldsymbol{P - 2}$} \\
\cline { 2 - 5 } & Pretest & Posttest & Pretest & Posttest \\
\hline Nilai Reliabilitas & 0,82 & 0,82 & 0,80 & 0,85 \\
Tingkat Reliabel & Bagus & Bagus & Bagus & Bagus \\
\hline
\end{tabular}

Setelah mengetahui tingkat validitas, kesukaran dan reliabel soal, selanjutnya adalah menghitung perolehan nilai dengan Ms. excel untuk mengetahui hasil profil kemampuan berpikir kritis sebelum dan sesudah implementasi model pembelajaran SETS 


\section{Pancasakti Science Education Journal, 4 (2), Oktober 2019- (140) \\ Mega Sylviana, Mobinta Kusuma, Bayu Widiyanto}

berbasis probing-prompting. Hasil tersebut dapat dilihat dari perolehan nilai rata-rata kemampuan pada saat pretest maupun posttest.
Hasil rata-rata profil kemampuan berpikir kritis dapat dilihat pada Gambar 1.

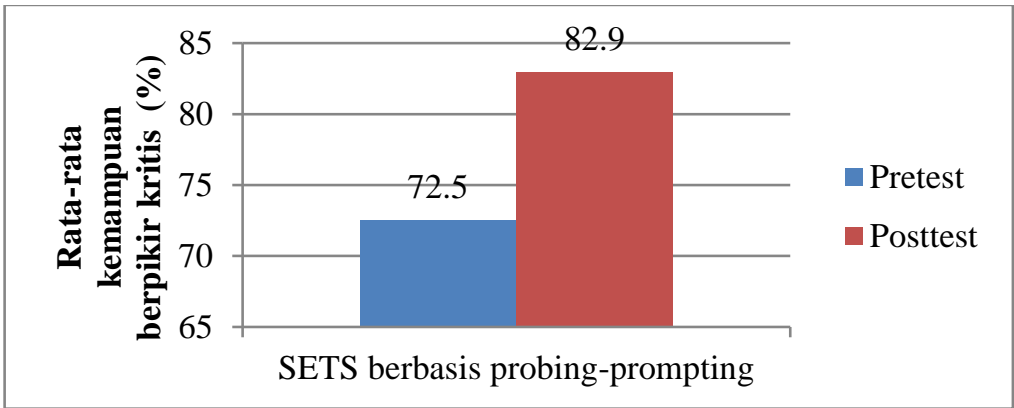

Gambar 1. Grafik Peningkatan Rata-rata Kemampuan Berpikir Kritis

Berdasarkan Gambar 1 perolehan nilai rata-rata kemampuan berpikir kritis siswa mengalami peningkatan. Nilai rata-rata pada saat pretest tergolong tinggi yaitu sebesar $72.5 \%$. Sedangkan nilai rata-rata pada saat posttest tergolong sangat tinggi yaitu sebesar $82.9 \%$. Hal tersebut sejalan dengan penelitian yang dilakukan Hidayatullah, Raga, \& Mahadewi (2014) dan Rahmadi (2016) bahwa probing-prompting berpengaruh terhadap kemampuan berpikir kritis siswa. Adapun hasil persentase rata-rata nilai kemampuan berpikir kritis pretest-posttest pada setiap indikator dapat dilihat pada Gambar 2.

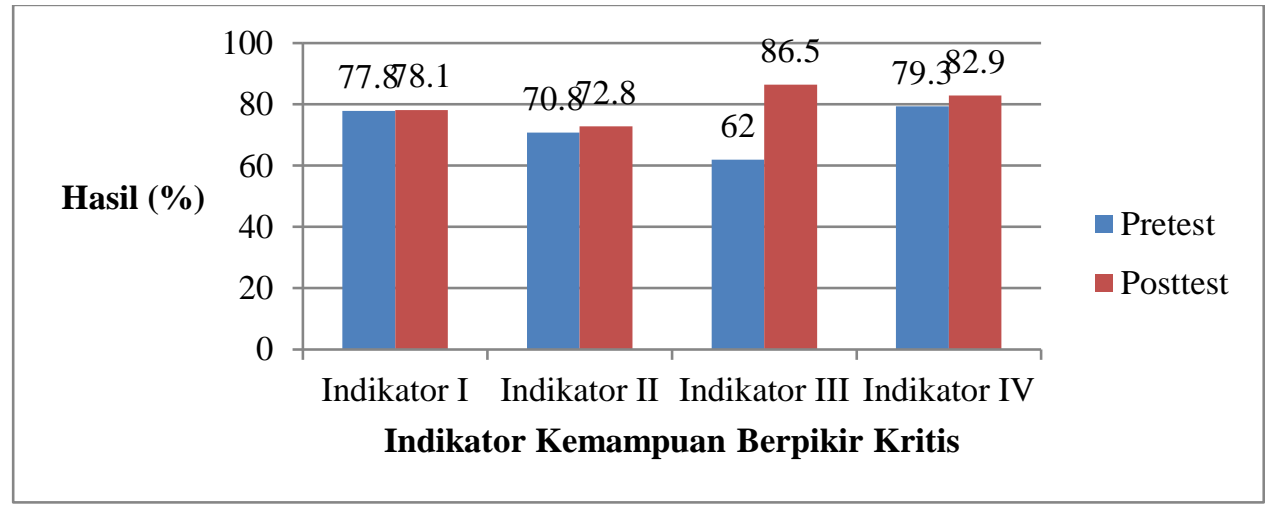

Gambar 2. Grafik Profil Kemampuan Berpikir Kritis Siswa

Berdasarkan Gambar 2 perolehan ratarata kemampuan berpikir kritis ke-empat indikator kemampuan berpikir kritis yang digunakan mengalami kenaikan. Pada indikator I yaitu menganalisis pertanyaan dan pernyataan, hasil rata-rata pretest sebesar $77.8 \%$ termasuk dalam kategori tinggi dan rata-rata posttest sebesar $78.1 \%$ termasuk dalam kategori tinggi. Hasil tersebut dapat dilihat berdasarkan perolehan nilai tes tertulis siswa setelah perlakuan. Indikator II yaitu bertanya dan menjawab klarifikasi atau tantangan pertanyaan, hasil rata-rata pretest sebesar $70.8 \%$ termasuk dalam kategori tinggi dan rata-rata posttest sebesar $72.3 \%$ termasuk dalam kategori tinggi. Hasil tersebut dapat dilihat dari keterlibatan siswa pada proses pembelajaran. Keterlibatan siswa terjalin pada saat proses tanya jawab yang dilakukan, baik dari guru ke siswa maupun dari siswa ke siswa. Indikator III yaitu mengamati dan mempertimbangkan pengamatan laporan, hasil rata-rata pretest sebesar $62.0 \%$ termasuk dalam kategori tinggi dan rata-rata posttest sebesar $94.8 \%$ termasuk dalam kategori sangat tinggi. Hasil tersebut dapat dilihat dari pengamatan praktikum yang 


\section{Pancasakti Science Education Journal, 4 (2), Oktober 2019- (141)}

Mega Sylviana, Mobinta Kusuma, Bayu Widiyanto

dilaksanakan. Siswa secara langsung mengamati setiap langkah yang dilakukan selama praktikum, dan mulai berdiskusi aktif mengenai kejadian yang terjadi selama praktikum. Sedangkan pada indikator IV yaitu menyimpulkan dan mempertimbangkan kesimpulan secara umum, hasil rata-rata pretest sebesar $79.3 \%$ termasuk dalam kategori tinggi dan rata-rata posttest sebesar $86.6 \%$ termasuk dalam kategori sangat tinggi. Hasil tersebut dapat dilihat dari cara siswa menyimpulkan suatu pernyataan atau pertanyaan.

Kemampuan berpikir kritis siswa naik $10.4 \%$, yaitu pada pretest sebesar $72.5 \%$ termasuk dalam kategori tinggi, pada posttest sebesar $82.9 \%$ termasuk dalam kategori sangat tinggi. Sehingga dapat disimpulkan bahwa profil kemampuan berpikir kritis siswa mengalami kenaikan setelah implementasi model pembelajaran SETS berbasis probingprompting.

Perolehan hasil pengujian di latarbelakangi oleh perbedaan penggunaan model pembelajaran yang diterapkan. Seperti yang telah dijelaskan sebelumnya model pembelajaran yang diterapkan adalah model SETS berbasis probing-prompting. Model ini memberikan kesempatan secara aktif kepada siswa untuk bertanya dan menjawab pertanyaan. Sehingga siswa dapat terlibat dalam proses pembelajaran dan kemampuan berpikir kritis dapat lebih terasah. Hal tersebut sejalan dengan Terenzini (1993) bahwa tingkat keterlibatan siswa baik di dalam maupun di luar kelas memiliki efek penting pada berbagai bentuk pengembangan kognitif termasuk kemampuan berpikir kritis. Dibuktikan dengan pernyataan Pascarella \& Terezini (1991) bahwa berpikir kritis melibatkan kemampuan individu untuk melakukan hal berikut : mengidentifikasi masalah dan mengasumsi argumen, mengenali hubungan penting, membuat kesimpulan yang benar dari data, menarik kesimpulan dari informasi atau data yang diberikan, menginterpretasikan apakah kesimpulan dijamin berdasarkan data yang diberikan, dan mengevaluasi bukti. Dan dalam penelitian
Dewi \& Riandi (2015) dan Maimunah (2016) yang menyatakan bahwa dengan kemampuan berpikir kritis, siswa dapat menyikapi, mengolah informasi dan memecahkan atau menyelesaikan permasalahan.

Implementasi SETS dapat membantu siswa dalam memahami pembelajaran karena pembelajaran dikaitkan dengan permasalahan yang ada dalam kehidupan sehari-hari (Aprianingtyas \& Sumadi, 2017), yang didukung oleh Birgili (2015) bahwa dengan masalah sehari-hari siswa memiliki kesempatan untuk menemukan pengetahuan baru, memecahkan suatu masalah dan berpartisipasi aktif dalam menciptakan solusi untuk menyelesaikan masalah melalui pengalaman. Sedangkan probing-prompting membantu siswa agar lebih aktif dalam bertanya atau menjawab pertanyaan (Kariani, Putra, \& Ardana, 2014), baik yang diberikan oleh guru kepada siswa maupun dari siswa ke siswa.

\section{SIMPULAN}

Adapun simpulan penelitian profil kemampuan berpikir kritis siswa dengan implementasi model pembelajaran SETS berbasis probing-prompting adalah hasil analisis kemampuan berpikir kritis yang dilakukan menunjukkan profil kemampuan berpikir kritis siswa setelah implementasi model pembelajaran SETS berbasis probing-prompting meningkat, yaitu sebesar $10.4 \%$

Saran yang dapat disampaikan yaitu masih diperlukan upaya penelitian lanjutan guna implementasi model pembelajaran SETS berbasis probing-prompting untuk tema lainnya. Pengujian juga perlu dilakukan untuk skala yang lebih luas dengan jumlah sampel yang lebih banyak serta pengaturan estimasi waktu agar lebih efisien.

\section{DAFTAR PUSTAKA}

Aprianingtyas, M., \& Sumadi, S. (2017). Pengaruh Model Pembelajaran (Science, Environment, Technology, And Society) Terhadap Prestasi Belajar Fisika Pokok 
Pancasakti Science Education Journal, 4 (2), Oktober 2019- (142)

Mega Sylviana, Mobinta Kusuma, Bayu Widiyanto

Bahasan Tekanan. Compton: Jurnal Ilmiah Pendidikan Fisika, 3(2).

Birgili. (2015). Creative an Critical Thinking Skills in Problem-based Learning Environments. Journal of Gifted Education and Creativity, 2(2).

Dewi, N., \& Riandi. (2015). Analisis Kemampuan Berpikir Kritis Sains Siswa SMP Kelas VII di Kota Sukabumi Melalui Pembelajaran Berbasis Masalah pada Tema Pemanasan Global. Prosiding Seminar Nasional Fisika (E-Journal) SNF2015, 4.

Ennis, R. H. (2011). The Nature of Critical Thinking: An Outline of Critical Thinking Dispositions. Sixth International Conference on Thinking at MIT.

Hambleton, R. ., \& Swaminathan, H. (1985). Fundamentals of Item Response Theory. London: Sage Publications.

Hidayatullah, P. A. A., Raga, G., \& Mahadewi, L. P. P. (2014). Pengaruh Model Probingprompting terhadap Kemampuan Berpikir kritis siswa pada mata pelajaran IPA kelas V. E-Journal MIMBAR PGSD Universitas Pendidikan Ganesha, 2(1).

Huda, M. (2014). Model-model pembelajaran: isuisu metodis dan paradigmatis. Yogyakarta: Alfabeta.

Kariani, N. K., Putra, S., \& Ardana, I. K. (2014). Model Problem Based Learning Menggunakan Metode ProbingPrompting Berpengaruh Terhadap Hasil Belajar IPA Siswa. MIMBAR PGSD Undiksha, 2(1).

Kusuma, M. (2016). Pengembangan Perangkat Penilaian Peta Konsep Untuk Mengevaluasi Proses Berpikir Pada Topik
Animalia. PSEJ (Pancasakti Science Education Journal), 1(1).

Maimunah. (2016). Penggunaan Model Pembelajaran Science Environment Technology and Society (SETS) untuk Meningkatkan Kemampuan Berpikir Kritis dan Sikap Ilmiah. Jurnal Formatif, 6 (2).

Pascarella, E., \& Terezini, P. T. (1991). How College Affects Students: Findings and Insights from Twenty Years of Research. San Francisco: Jossey-Bass.

Rahmadi, T. N. (2016). Pengaruh Penerapan Metode Probing-prompting pada pembelajaran IPA SMP Kelas VII terhadap Kemampuan Berpikir Kritis Siswa. Jurnal Pendidikan Matematika Dan Sains, 1.

Steele, A. (2013). Shifting Currents: Science Technology Society and Environment in Northern Ontario Schools. Brock Education, 23(1).

Susongko, P. (2015). Pengantar Metodologi Penelitian Pendidikan. Tegal: Badan Penerbitan Universitas Pancasakti Tegal.

Terenzini, P. T. (1993). Influences Affecting the Development of Student' Critical Thinking Skills. Paper Present at the Association for Institutional Research (New Orleans, LA, May 1993).

Tim Pengembang MKDP. (2011). Kurikulum dan Pembelajaran. Bandung: FIP UPI.

Wahyuni, S. (2015). Pengembangan Bahan Ajar IPA Untuk Meningkatkan Kemampuan Berpikir Kritis Siswa SMP. Prosiding Seminar Nasional Fisika Dan Pendidikan Fisika (SNFPF) Ke-6, 6(1). 